\title{
Uranium fate during crystallization of magnetite from ferrihydrite in conditions relevant to the disposal of radioactive waste
}

Timothy A. Marshall ${ }^{1}$, Katherine Morris ${ }^{1}$, Gareth T.W. LaW ${ }^{2}$, J. Frederick W. Mosselmans ${ }^{3}$, Pieter Bots ${ }^{1}$, Hannah Roberts ${ }^{1}$ and SAmUel Shaw ${ }^{1, *}$

1 Research Centre for Radwaste Disposal and Williamson Research Centre for Molecular Environmental Science, School of Earth, Atmospheric and Environmental Science, The University of Manchester, Manchester M13 9PL, United Kingdom

2 Centre for Radiochemistry Research, School of Chemistry and Research Centre for Radwaste Disposal, School of Earth, Atmospheric and Environmental Science, The University of Manchester, Manchester M13 9PL, United Kingdom

3 Diamond Light Source Ltd, Diamond House, Harwell Science and Innovation Campus, Didcot, Oxfordshire OX11 0DE, United Kingdom

[Received 5 November 2014; Accepted 29 June 2015; Associate Editor: Nicholas Evans]

\section{ABSTRACT}

Uranium incorporation into magnetite and its behaviour during subsequent oxidation has been investigated at high $\mathrm{pH}$ to determine the uranium retention mechanism(s) on formation and oxidative perturbation of magnetite in systems relevant to radioactive waste disposal. Ferrihydrite was exposed to U(VI) $)_{\mathrm{aq}}$ containing cement leachates ( $\mathrm{pH} 10.5-13.1)$ and crystallization of magnetite was induced via addition of $\mathrm{Fe}(\mathrm{II})_{\mathrm{aq}}$. A combination of XRD, chemical extraction and XAS techniques provided direct evidence that U(VI) was reduced and incorporated into the magnetite structure, possibly as $\mathrm{U}(\mathrm{V})$, with a significant fraction recalcitrant to oxidative remobilization. Immobilization of $U(V I)$ by reduction and incorporation into magnetite at high $\mathrm{pH}$, and with significant stability upon reoxidation, has clear and important implications for limiting uranium migration in geological disposal of radioactive wastes.

KEYWoRDs: uranium, magnetite, incorporation, EXAFS, radioactive waste, geodisposal.

\section{Introduction}

DuE to its long half-life and significance in the nuclear fuel cycle, uranium is the dominant radionuclide by mass in a geological disposal facility (GDF). In addition, uranium is a significant contaminant at many nuclear facilities. In terms of

*E-mail:sam.shaw@manchester.ac.uk DOI: 10.1180/minmag.2015.079.6.02 environmental behaviour, under oxic conditions $\mathrm{U}(\mathrm{VI})$ is dominant and is relatively soluble in aqueous solution and can form neutral and anionic carbonate complexes which make it environmentally mobile (Clark et al., 1995); however, sparingly soluble uranyl silicates and uranate phases can also form in some natural/ engineered environments (e.g. high-pH cementious conditions, Wellman et al., 2007). Under reducing conditions U(IV) dominates, which is sparingly soluble and may precipitate as U(IV) oxide phases
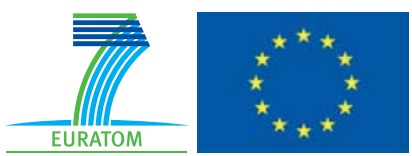

The publication of this research has been funded by the European Union's European Atomic Energy Community's (Euratom) Seventh Framework programme FP7 (2007-2013) under grant agreements $n^{\circ} 249396$, SecIGD, and $n^{\circ} 323260$, SeclGD2. 
(Murphy and Shock, 1999; Lloyd and Renshaw, 2005). Additionally, formation of stable uranium colloids may also promote migration of uranium in cementitious environments (Bots et al., 2014; Smith et al., 2014).

Uranium adsorbs to a wide range of geological materials under oxic and reducing conditions (Payne et al., 1994; Waite et al., 1994; Shuibo et al., 2009). In addition, both goethite $(\alpha-\mathrm{FeOOH})$ and hematite $\left(\alpha-\mathrm{Fe}_{2} \mathrm{O}_{3}\right)$ have been shown to be capable of incorporating $\mathrm{U}(\mathrm{VI})$ and $\mathrm{U}(\mathrm{V})$ into their structures, offering a pathway for long-term immobilization (Nico et al., 2009; Boland et al., 2011, 2014; Ilton et al., 2012; Marshall et al., $2014 b)$. Magnetite $\left(\mathrm{Fe}_{3} \mathrm{O}_{4}\right)$ is a mixed $\mathrm{Fe}(\mathrm{II}) / \mathrm{Fe}(\mathrm{III})$ oxide (Fleet, 1981; Cornell and Schwertmann, 2003) relevant in both natural and engineered environments and its interactions with uranium have been explored by several workers. Magnetite can remove $\mathrm{U}(\mathrm{VI})$ from solution through reduction to $\mathrm{U}(\mathrm{IV})$ coupled to oxidation of Fe(II), with precipitation of $\mathrm{UO}_{2}$ on the magnetite surface (Dodge et al., 2002; Missana et al., 2003; Scott et al., 2005; Skomurski et al., 2011; Singer et al., 2012a). Recent work has shown that at low uranium loadings, mononuclear U(IV) complexes form on the magnetite surface which then nucleate the precipitation of $\mathrm{UO}_{2}$ as the surface loading increases (Latta et al., 2014). Indeed, with time, it appears that adsorbed uranium may become incorporated into the magnetite structure with XPS suggesting $\mathrm{U}(\mathrm{VI})$ and $\mathrm{U}(\mathrm{V})$, and XANES suggesting $\mathrm{U}(\mathrm{IV})$ and $\mathrm{U}(\mathrm{V}) / \mathrm{U}(\mathrm{VI})$. EXAFS modelling was more challenging but the authors suggested that $\mathrm{U}$ was incorporated into the magnetite octahedral site (Huber et al., 2012).

$\mathrm{U}(\mathrm{IV})$ associated with iron oxide minerals as $\mathrm{UO}_{2}$ is easily remobilized to solution under oxidizing, and potentially even mildly reducing conditions (Senko et al., 2002, 2007; Campbell et al., 2011). By contrast, if $U$ is incorporated within the mineral, it may be protected from oxidative release, as observed with goethite (Stewart et al., 2009). Many geodisposal concepts utilize cementitious materials in the design of the disposal facility, e.g. an engineered barrier system. Leaching of the cement will cause hyperalkaline $\mathrm{pH}$ from $>13$ to 10 over geological time, creating a chemically disturbed zone in the host rock (Berner, 1992). In addition, radioactively contaminated land can be alkaline (Catalano et al., 2004; Wallace et al., 2012, 2013). In addition, magnetite will undoubtedly be important in any geological disposal facility as anaerobic corrosion of steel leads to the formation of magnetite (Music et al., 1993). However, to date few studies have examined the structural environment of $U$ incorporated into magnetite and the effect of oxidation of the host mineral under alkaline conditions. Understanding this is important to enable prediction of the long-term stability and environmental fate of $\mathrm{U}$ in geodisposal relevant situations.

Here, we examine incorporation of $U$ into magnetite under alkaline conditions to explore the speciation of the incorporated $\mathrm{U}$, the effects of changing $\mathrm{pH}$, the amount of $\mathrm{U}$ sequestered, and the fate of $U$ following air oxidation. Ferrihydrite has been used as the starting material and magnetite was crystallized by addition of aqueous $\mathrm{Fe}(\mathrm{II})$ (Hansel et al., 2003). We have followed the partitioning of $U$ during this process in two solutions at $\mathrm{pH} 13.1$ and 10.5. After a period of ageing, the systems were then oxidized in air to test the recalcitrance of any iron-oxide-associated uranium. We have combined solution chemistry data with quantitative powder X-ray diffraction (qXRD), transmission electron microscopy (TEM), and X-ray absorption spectroscopy (XAS) to characterize the fate of uranium during magnetite crystallization and reoxidation at high $\mathrm{pH}$.

\section{Materials and methods}

The Fe(II)-induced crystallization of ferrihydrite to magnetite was studied in U(VI)-amended synthetic cement leachates chosen to simulate early$(\mathrm{pH} 13.1)$ and late- $(\mathrm{pH}$ 10.5) stage evolution of a GDF (Berner, 1992; Marshall et al., 2014a; Moyce et al., 2014). The young cement leachate (YCL, pH 13.1) is dominated by potassium and sodium hydroxide dissolution and the old cement leachate (OCL, $\mathrm{pH}$ 10.5) is dominated by calcium hydroxide. The YCL composition was: $5.2 \mathrm{~g} \mathrm{l}^{-1}$ $\mathrm{KOH}, 3.8 \mathrm{~g} \mathrm{l}^{-1} \mathrm{NaOH}$ and $0.1 \mathrm{~g} \mathrm{l}^{-1} \mathrm{Ca}(\mathrm{OH})_{2}$; the OCL composition was: $15 \mathrm{mg}^{-1} \mathrm{Ca}(\mathrm{OH})_{2}$. Experiments were maintained in an anaerobic atmosphere with $<1 \mathrm{ppm} \mathrm{O}_{2}$ and $\mathrm{CO}_{2}$.

2-line ferrihydrite was synthesized (Cornell and Schwertmann, 2003) and the Fe(III) content was determined by dissolution in $1 \mathrm{M} \mathrm{HCl}$ and analysis (Viollier et al., 2000). Ferrihydrite was equilibrated with the cement leachates at $4 \mathrm{~g} \mathrm{l}^{-1}$ for 1 hour at room temperature. A pH drop of 1-2 $\mathrm{pH}$ units in the OCL occurred over 2 hours and the system was manually readjusted to $\mathrm{pH} 10.5$ with $\mathrm{KOH}$. The $\mathrm{pH}$ was constant in the YCL. In the coprecipitation experiments, the ferrihydrite-equilibrated leachates were 
spiked with $\mathrm{U}(\mathrm{VI})$ to $4 \mathrm{ppm}\left(1.7 \times 10^{-5} \mathrm{~mol}^{-1}\right)$. Crystallization of magnetite was then induced by addition of $\mathrm{Fe}(\mathrm{II})$ as $0.1 \mathrm{M} \mathrm{FeCl} 2$, to give stoichiometric magnetite $[1 \mathrm{Fe}(\mathrm{II}): 2 \mathrm{Fe}(\mathrm{III})]$ and $\mathrm{pH}$ was immediately re-adjusted using $\mathrm{KOH}$. The magnetite was aged for two days in an anaerobic $\mathrm{CO}_{2}$-free environment and then moved to a $\mathrm{CO}_{2}$-free air (Zero Grade Air) environment and oxidized for 14 days. Parallel unspiked experiments for full characterization of the solid products were set up and the data presented in Marshall et al. (2014a). Sorption 'controls' were also set up where U(VI) was spiked after 1 day of magnetite ageing and left for one further day before reoxidation in $\mathrm{CO}_{2}$-free air for 14 days.

Partitioning of uranium between the solid and solution was determined by analysis of the solution U concentration by ICP-MS (Agilent 7500cx). The uranium distribution in the solid phase was determined by a dissolution time-series of the solid samples in $1 \mathrm{M} \mathrm{HCl}$ and the solution analysed for $\mathrm{U}$ and Fe by ICP-MS, after the method of Sidhu et al. (1978). Solids were characterized by X-ray Diffraction (XRD) using a Bruker D8 diffractometer. For TEM, solid samples were characterized using an FEI CM200 FEG-TEM. Uranium $L_{\mathrm{III}^{-}}$ edge XAS spectra were collected at B18, Diamond Light Source, at room temperature in fluorescence mode using a 9-element Ge detector (Dent et al., 2009). U(VI) and U(IV) standard spectra (schoepite $\left[\left(\mathrm{UO}_{2}\right)_{8} \mathrm{O}_{2}(\mathrm{OH})_{12} \cdot 12\left(\mathrm{H}_{2} \mathrm{O}\right)\right]$ and uraninite $\left(\mathrm{UO}_{2}\right)$,

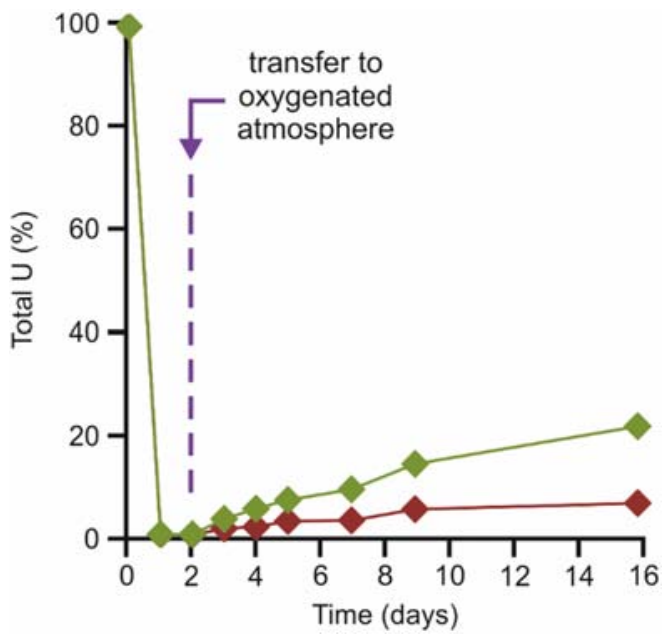

Fig. 1. Concentration of $U$ in solution (\%) during magnetite ageing (days $0-2$ ), and subsequent air oxidation (days 2-16) in YCL (red) and OCL (green). respectively) were collected in transmission mode. Data reduction and fitting of the EXAFS spectra were performed using Athena and Artemis (Ravel and Newville, 2005) with FEFF6.

\section{Results and discussion}

All uranium was removed from solution during the reduced stage in both systems (Fig. 1). After 14 days reoxidation, $6 \pm 1 \%$ and $21 \pm 1 \%$ of the uranium was remobilized to solution in the YCL and OCL, respectively (Fig. 1). Acid digestions on the reduced and oxidized magnetites, from both systems, were used to explore the $\mathrm{U}$ distribution profile in the solids (Fig. 2). In the YCL system, the gradient of 1 suggested that $U$ was uniformly distributed through the particles and oxidation of the host mineral had no effect on the $U$ distribution (Fig. 2). $U$ distribution through the reduced magnetite particles in the OCL system also shows a uniform concentration throughout the particles. After 21 days oxidation in the OCL system the leaching data suggested that the distribution of $U$ changed significantly with $\sim 15 \%$ of the $U$ released before any significant dissolution of $\mathrm{Fe}$ $(<2 \%)$. This was then followed by a more uniform distribution of $U$ within the particles. These data indicate that $\sim 15 \%$ of the $\mathrm{U}$ was associated with the surface of the iron oxide particles (Fig. 2). This is consistent with the observation that after 21 days oxidation, $21 \%$ of the total $U$ was present in solution so that 'available' solution-associated U could readsorb to the oxidized magnetite surface.

In the YCL system no pool of $1 \mathrm{M} \mathrm{HCl} \mathrm{extractable}$ adsorbed $U$ was evident in the oxidized sample. The extent of magnetite oxidation in the YCL system after 21 days oxidation was limited, whereas in the OCL there was appreciable magnetite oxidation over the same period (Marshall et al., 2014a). Different magnetite oxidation rates in the different leachates may explain the different behaviour of $U$; the extent of oxidation and hence oxidative release of $U$ to solution is lower in the YCL, but additionally, any remobilized U(VI) may form colloidal U(VI) phases (Bots et al., 2014) and limit re-adsorption behaviour with the magnetite.

Magnetite oxidation to maghemite proceeds via outward migration of $\mathrm{Fe}$ (II) (Sidhu et al., 1977; Tang et al., 2003; Gorski et al., 2010). During the oxidation process, $\mathrm{U}$ is likely to be expelled from the particle core as the structure re-orders itself owing to the larger crystal radius of $U$ versus Fe (Shannon, 1976). U(VI) and U(IV) have crystal radii (in octahedral coordination) of $0.87 \AA$ and 

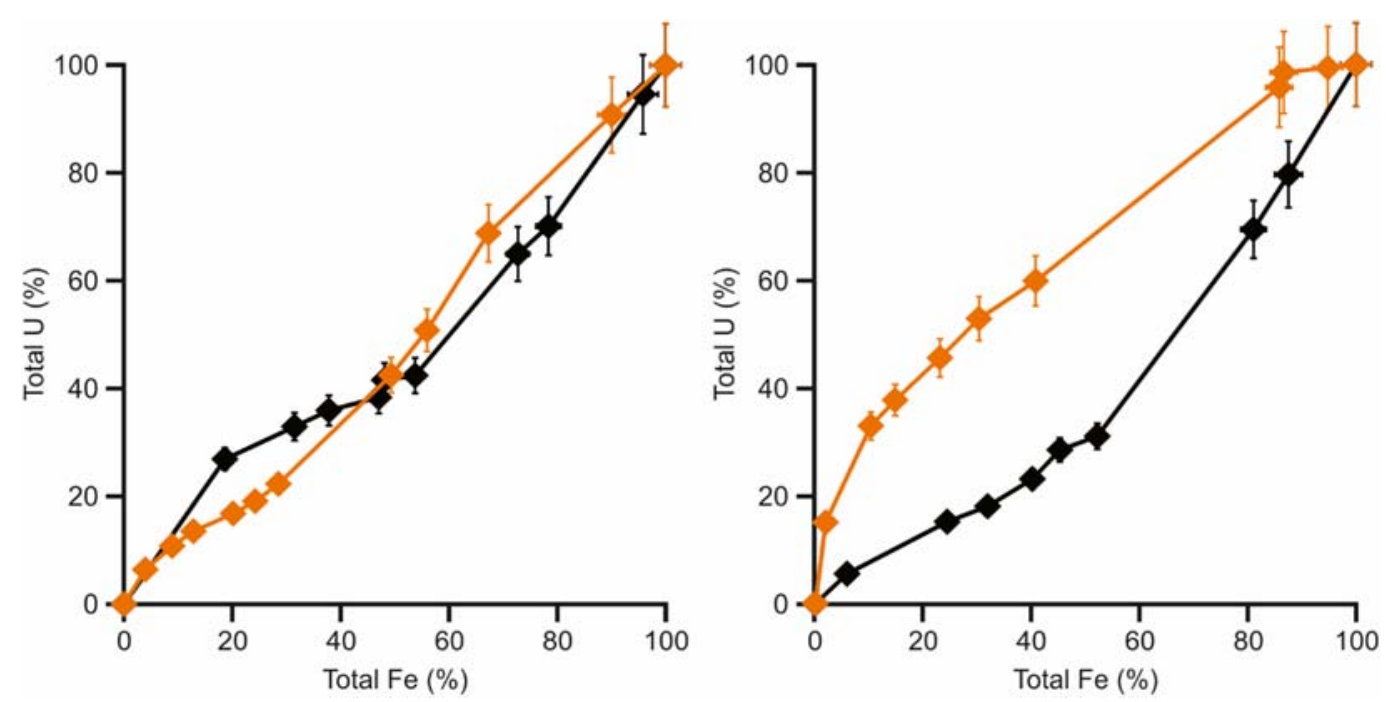

FIG. 2. Release of $\mathrm{U}$ and total Fe during dissolution of magnetite in $1 \mathrm{M} \mathrm{HCl}$ in the YCL system ( $\mathrm{pH}$ 13.1) (left) and OCL system ( $\mathrm{pH}$ 10.5) (right). Black lines are reduced magnetite experiments, orange lines are oxidized magnetite experiments.

$1.03 \AA$, respectively, whilst the crystal radii of $\mathrm{Fe}(\mathrm{III})$ and $\mathrm{Fe}(\mathrm{II})$ (in octahedral coordination, high spin) are $0.785 \AA$ and $0.92 \AA$, respectively (Shannon, 1976). However, the uniform distribution of $U$ in the oxidized samples, particularly in the OCL system, suggests that the majority of $U$ is retained during oxidation and it is not ejected from the structure (Fig. 2). It has been suggested that the comparative ionic charge, radii and electronegativity all have an influence on the substitution behaviour of different elements within host minerals (Sidhu et al., 1978). In magnetite, similar uniform distributions have been observed for $\mathrm{Co}, \mathrm{Ni}$ and $\mathrm{Zn}$, whereas $\mathrm{Cu}, \mathrm{Mn}$ and $\mathrm{Cd}$ have been observed to have a dominant surface accumulation (Sidhu et al., 1978). Recently, Tc was also observed to have a near surface distribution predominance (Marshall et al., 2014a).

\section{X-ray absorption spectroscopy}

$\mathrm{U} L_{\mathrm{III}}$-edge XANES and EXAFS spectra were collected on reduced magnetite from the YCL and OCL coprecipitation and adsorption experiments, along with an oxidized magnetite from the OCL coprecipitation experiment. The XANES spectra are shown in Fig. 3 with the U(VI) and U(IV) reference spectra. It is clear that in all experiments U(VI) reduction occurred with an obvious shift in the energy of the adsorption edge of all experimental spectra towards that of the U(IV) standard (Fig. 3). Interestingly, the edge position of the three coprecipitation experiments' spectra $[(d)-(f)]$ were $\sim 1 \mathrm{eV}$ higher than the U(IV) standard and the parallel adsorption experiments $[(a)-(c)]$. This higher edge energy could potentially result from either mixed valence $\mathrm{U}$ in multiple sites within the sample [e.g. incorporated U(IV) and adsorbed (U(VI)] or it could indicate $\mathrm{U}(\mathrm{V})$ stabilized through incorporation into the magnetite structure (Huber et al., 2012), and which has also been reported for other iron oxides (Ilton et al., 2010, 2012; Boland et al., 2014). Additionally, the coprecipitation spectra displayed a broad white line with a shoulder on the rising edge (Fig. 3) that was absent in the sorption samples. This has been attributed to $\mathrm{U}(\mathrm{V})$ or $\mathrm{U}(\mathrm{VI})$ in octahedral uranate coordination (Van den Berghe et al., 2002; Soldatov et al., 2007). Therefore, both the partial shift to lower absorption edge energy, and the shoulder feature in the coprecipitation experiments suggest that $\mathrm{U}(\mathrm{V})$ may be present within the samples with uranatelike coordination. The YCL adsorption sample also displayed a broad white line, although there was no clear shoulder on the rising edge and the edge position was aligned to the U(IV) reference. In contrast to the coprecipitation experiments, this suggests that the dominant signal was from $\mathrm{U}(\mathrm{IV})$, likely to be $\mathrm{UO}_{2}$ but the broadening of the white line may indicate a small 

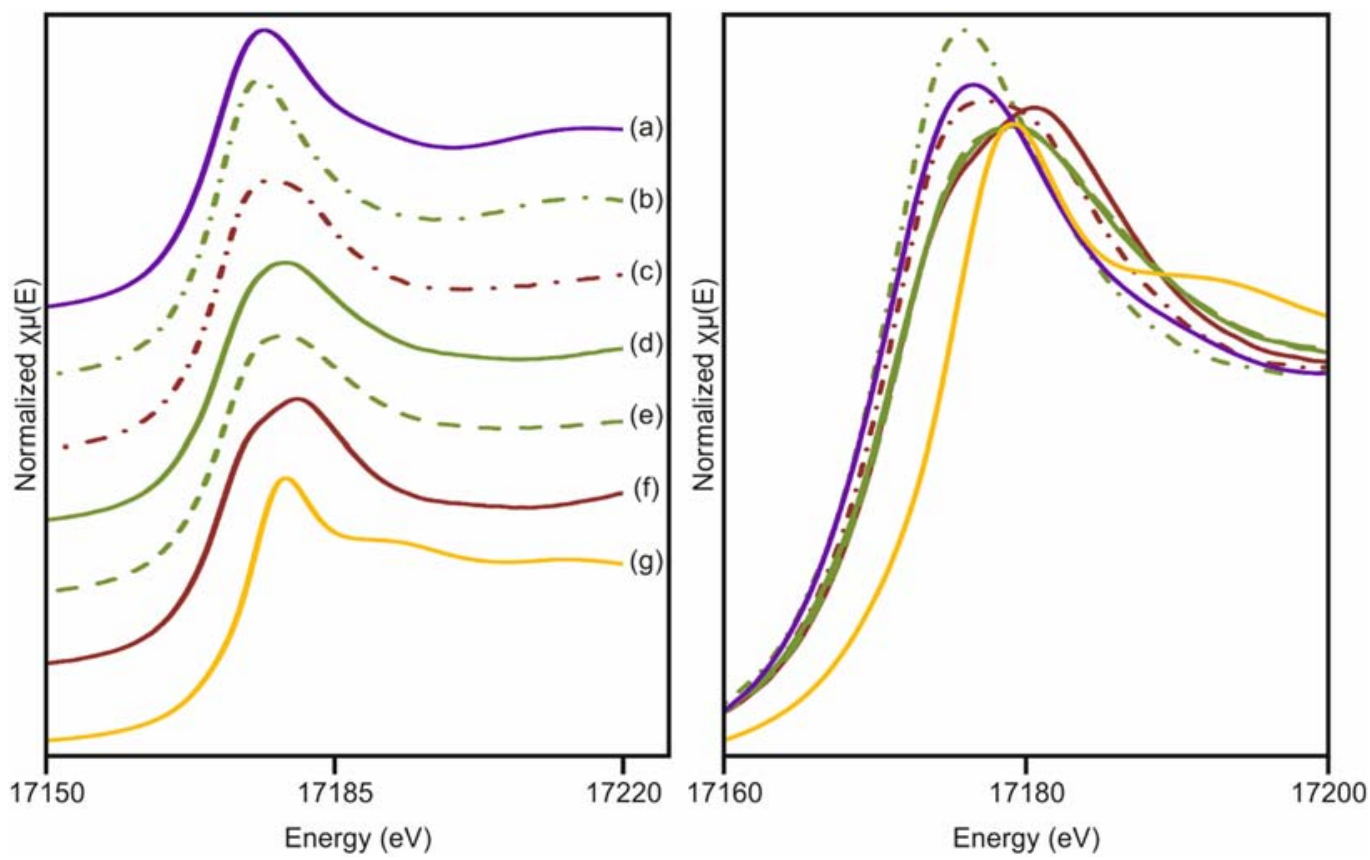

FIG. 3. U $L_{\mathrm{III}}$-edge XANES spectra; ( $a$ ) uraninite (U(IV) reference); (b) OCL adsorption; (c) YCL adsorption; (d) OCL coprecipitation reduced; $(e)$ OCL coprecipitation oxidized; $(f)$ YCL coprecipitation reduced; $(g)$ schoepite (U(VI) reference).
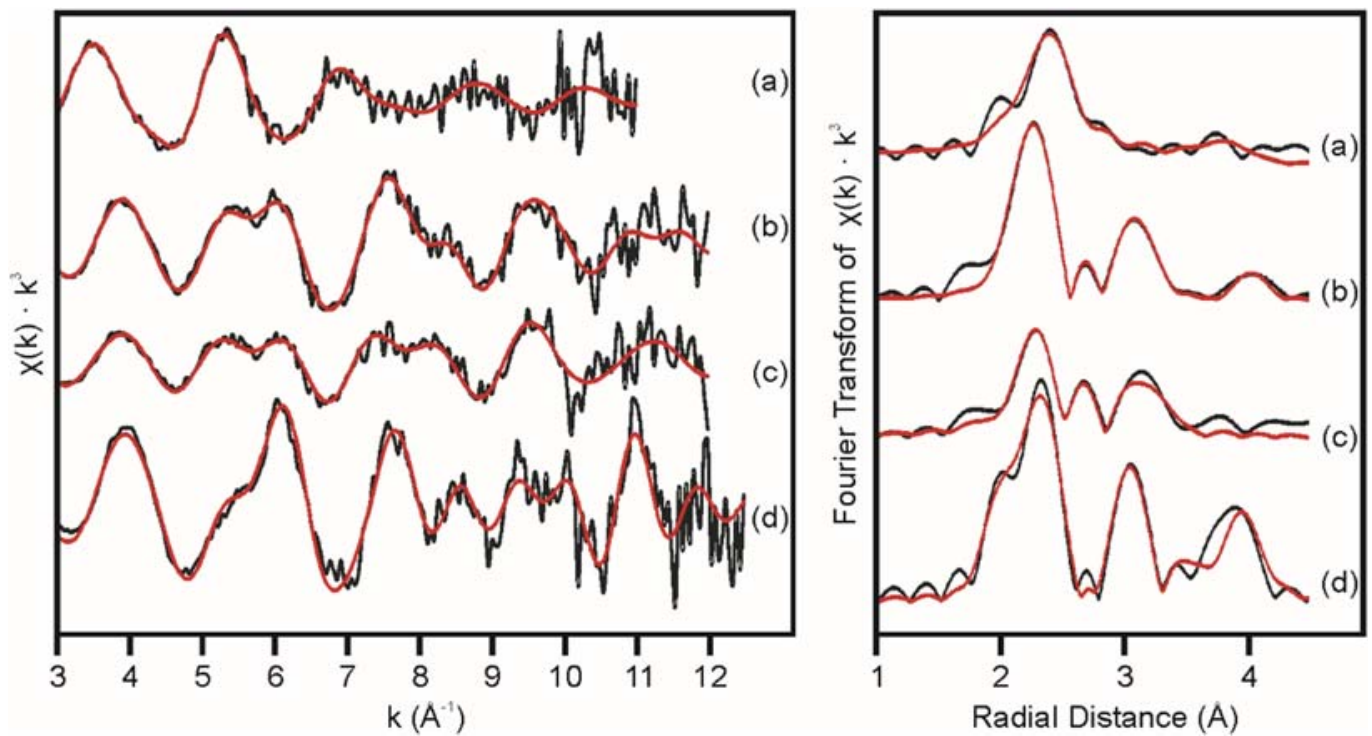

FIG. 4. U $L_{\text {III }}$-edge k3-weighted EXAFS spectra (left) and Fourier transforms plotted without a phase shift (right). Black lines are data and red lines are fits to the data; (a) OCL adsorption; (b) OCL coprecipitation reduced; (c) OCL coprecipitation oxidized; (d) YCL coprecipitation reduced. 
proportion of the $\mathrm{U}$ becoming incorporated into the magnetite as a result of dynamic equilibrium or crystal ageing (e.g. Ostwald ripening; Kahlweit, 1975).

The EXAFS data and the respective fits for each sample are shown in Fig. 4, and the refined fit parameters are given in Table 1. The OCL adsorption sample is markedly different from the other spectra, lacking a peak in the EXAFS at $\mathrm{k} \approx 6 \AA^{-1}$, and also lacking a peak in the Fourier transform (FT) at $3 \AA$. It was expected that $\mathrm{UO}_{2}$ would reductively precipitate on the preformed magnetite surface (Singer et al., 2012b; Latta et al., 2014) and this sample was best fit using the uraninite $\left(\mathrm{UO}_{2}\right)$ structure with the addition of an $\mathrm{Fe}$ shell at $2.97 \AA$ (Table 1). Interestingly, the addition of an $\mathrm{Fe}$ shell suggests that some component of U(IV) was present as an adsorbed species (Latta et al., 2014). Note that due to the lower quality of the data from the OCL adsorption sample it was not possible to achieve a reasonable fit while refining all parameters simultaneously; therefore the coordination numbers for each shell were changed systematically until the best fit to the data was achieved using the model of $\mathrm{UO}_{2}$ (Singer et al., $2012 b$ ) and U(IV) adsorbed to magnetite (Latta et al., 2014) as the underlying structural models. Fitting of the reduced OCL coprecipitated sample assumed incorporation of $\mathrm{U}$ into the magnetite octahedral site (Fleet, 1981). The refined U-Fe distances for the two Fe shells ( $3.21 \AA$ and $3.46 \AA$ ) in this fit corresponded well to the $\mathrm{Fe}-\mathrm{Fe}$ distances in octahedral magnetite $(2.97 \AA$ and $3.48 \AA)$. The longer U-Fe distance of the first shell (3.21 $\AA$ versus $2.97 \AA$ ) is presumably due to expansion of the octahedral site to accommodate $\mathrm{U}$ in place of $\mathrm{Fe}$, as predicted by Kerisit et al. (2011). The crystal radius depends upon the coordination and the oxidation state of the element in question; in six-fold coordination, U(IV), U(V) and U(VI) have crystal radii of $1.03 \AA, 0.90 \AA$ and $0.87 \AA$, respectively (Shannon, 1976), whilst the crystal radii of $\mathrm{Fe}(\mathrm{II})$ and $\mathrm{Fe}(\mathrm{III})$ in six-fold coordination (high spin) are $0.920 \AA$ and $0.785 \AA$, respectively (Shannon, 1976). Both $\mathrm{Fe}$ (II) and Fe(III) occupy the octahedral sites in the magnetite inverse spinel structure, but substitution of $U$ into the structure is likely to preferentially replace $\mathrm{Fe}(\mathrm{III})$ to aid charge balance. Indeed, the observed expansion of the site occurs in a similar way to other instances of metal incorporation (Dardenne et al., 2002; Walter et al., 2009). The presence of the shoulder on the rising edge in the XANES spectrum is not inconsistent with $\mathrm{U}(\mathrm{V})$ in the OCL reduced sample. However, the axial $\mathrm{U}-\mathrm{O}$ distance $(1.81 \pm 0.01 \AA)$ is very short compared to a $\mathrm{U}(\mathrm{V})$ uranyl distance (1.90-2.05 $\AA$; Burns et al.,
1997; Docrat et al., 1999). This may indicate that U(VI) is also present (Singer et al., 2012a). Additionally, a small contribution from a U-U shell was required at $3.95 \AA$ to fit the peak in the FT at around $4 \AA$ and attributed to a small component of $\mathrm{U}(\mathrm{IV})$ as uraninite, presumably formed at the magnetite surface. The coordination number of the second Fe shell $(3.1 \pm 1.5)$ is lower than expected (6), possibly due to the nanosize of the magnetite particles leading to a significant proportion of nearsurface incorporated U (Yanina and Rosso, 2008), and if some of the $\mathrm{U}$ is present as uraninite, this will also decrease the effective coordination numbers. The same model was applied to the OCL oxidized sample. The U-O distance of the uranyl shell lengthened to $1.87 \AA$, suggesting a diminished adsorbed U(VI) component and increased incorporated $\mathrm{U}(\mathrm{V})$ component. The Debye-Waller factor for this shell is relatively large which indicates a degree of static disorder from overlapping contributions at similar $\mathrm{U}-\mathrm{O}$ distances. The other $\mathrm{U}-\mathrm{O}$ shells remain relatively unchanged from the reduced model, as does the first Fe shell at $\sim 3.2$ $\AA$. However, a second Fe shell was not resolved in the fit and there was no uraninite component (Fig. 4). This suggests that oxidative dissolution of precipitated $\mathrm{UO}_{2}$ is the dominant mechanism for the elevated release of $U$ back into solution in this system.

The EXAFS data for the YCL reduced coprecipitated sample was not similar to the OCL reduced and oxidized samples, despite the obvious similarities in the XANES spectra. The FT of the YCL reduced sample has three distinct peaks which roughly correlate with the three peaks observed in the FT of the OCL reduced sample, but the relative magnitude of the peaks $>\mathrm{R}=2.5 \AA$ were greater in the YCL sample, particularly for the U-U shell ( $3^{\text {rd }}$ peak, $\sim 4 \AA$ ), indicating the presence of significant $\mathrm{U}-\mathrm{U}$ interactions. The EXAFS was best fit using similar U-O and U-Fe shells to the OCL reduced and oxidized samples (at $2.17 \AA$ and $3.12 \AA$, respectively) but also with contributions from a calcium-uranate phase comprising; one $\mathrm{U}-\mathrm{O}$ distance at $1.69 \AA$, two $\mathrm{Ca}$ at $3.41 \AA$, and two $\mathrm{U}-\mathrm{U}$ shells at between $3.8-4.2 \AA$, similar to the structure of Ca-clarkeite (Bots et al., 2014). Note that due to the complexity of this 2-site fit it was not possible to achieve a reasonable fit while refining all parameters simultaneously; therefore the coordination numbers for each shell were changed systematically until the best fit to the data was achieved. U(VI) in solution in the YCL ( $\mathrm{pH} 13.1)$ has been shown to be present as colloidal calcium 
TABLE 1. Details of EXAFS fit parameters of U adsorbed to, and coprecipitated with magnetite and subsequent air oxidation.

\begin{tabular}{|c|c|c|c|c|c|c|c|c|c|}
\hline & Sample & Path & $\mathrm{CN}$ & $\mathrm{R}+\Delta \mathrm{R}(\AA)$ & $\sigma^{2}(\AA 2)$ & $\Delta E_{0}(\mathrm{eV})$ & $\mathrm{S}^{2}$ & $\chi_{\mathrm{v}}^{2}$ & $R$ \\
\hline \multirow[t]{3}{*}{ (a) } & \multirow{3}{*}{$\begin{array}{c}\text { OCL } \\
\text { adsorption }\end{array}$} & $\mathrm{U}-\mathrm{O}_{1}$ & $5^{\mathrm{a}}$ & $2.33(1)$ & 0.013 (1) & \multirow[t]{3}{*}{$2.8 \pm 0.8$} & \multirow[t]{3}{*}{$1.00(0)$} & \multirow[t]{3}{*}{5.9} & \multirow[t]{3}{*}{0.013} \\
\hline & & $\mathrm{U}-\mathrm{Fe}_{1}$ & $1^{\mathrm{a}}$ & $2.97(2)$ & 0.014 (3) & & & & \\
\hline & & $\mathrm{U}-\mathrm{U}_{1}$ & $9^{\mathrm{a}}$ & $3.81(3)$ & 0.034 (4) & & & & \\
\hline \multirow[t]{6}{*}{ (b) } & \multirow{6}{*}{$\begin{array}{c}\text { OCL } \\
\text { co-ppt } \\
\text { reduced }\end{array}$} & $\mathrm{U}-\mathrm{O}_{1}$ & $1^{\mathrm{a}}$ & $1.81(1)$ & 0.006 (1) & \multirow{6}{*}{$14.4 \pm 1.3$} & \multirow[t]{6}{*}{$1.00(0)$} & \multirow[t]{6}{*}{18.8} & \multirow[t]{6}{*}{0.006} \\
\hline & & $\mathrm{U}-\mathrm{O}_{2}$ & $3.7(4)$ & $2.21(1)$ & $0.008(2)^{\mathrm{b}}$ & & & & \\
\hline & & $\mathrm{U}-\mathrm{O}_{3}$ & $2.0(4)$ & $2.44(3)$ & $0.008(2)^{\mathrm{b}}$ & & & & \\
\hline & & $\mathrm{U}-\mathrm{Fe}_{1}$ & $6.1(24)$ & $3.21(2)$ & $0.018(4)^{\mathrm{b}}$ & & & & \\
\hline & & $\mathrm{U}-\mathrm{Fe}_{2}$ & $3.1(15)$ & $3.46(4)$ & $0.018(4)^{\mathrm{b}}$ & & & & \\
\hline & & $\mathrm{U}-\mathrm{U}_{1}$ & $1^{\mathrm{a}}$ & 3.95 (3) & 0.007 (3) & & & & \\
\hline \multirow[t]{4}{*}{ (c) } & OCL & $\mathrm{U}-\mathrm{O}_{1}$ & $2^{\mathrm{a}}$ & $1.87(2)$ & $0.020(3)$ & \multirow[t]{4}{*}{$13.5 \pm 1.6$} & \multirow[t]{4}{*}{$1.00(0)$} & \multirow[t]{4}{*}{16.4} & \multirow[t]{4}{*}{0.023} \\
\hline & co-ppt & $\mathrm{U}-\mathrm{O}_{2}$ & $3.3(5)$ & $2.20(1)$ & $0.008(2)^{\mathrm{b}}$ & & & & \\
\hline & oxidized & $\mathrm{U}-\mathrm{O}_{3}$ & $2.6(5)$ & $2.45(2)$ & $0.008(2)^{b}$ & & & & \\
\hline & & $\mathrm{U}-\mathrm{Fe}_{1}$ & $2.5(4)$ & $3.23(2)$ & $0.015^{\mathrm{a}}$ & & & & \\
\hline \multirow[t]{6}{*}{ (d) } & YCL & $\mathrm{U}-\mathrm{O}_{1}$ & $1^{\mathrm{a}}$ & 1.69 (3) & 0.009 (5) & \multirow[t]{6}{*}{$11.2 \pm 1.2$} & \multirow[t]{6}{*}{$0.80(4)$} & \multirow[t]{6}{*}{40.8} & \multirow[t]{6}{*}{0.022} \\
\hline & co-ppt & $\mathrm{U}-\mathrm{O}_{2}$ & $5^{\mathrm{a}}$ & 2.19 (1) & 0.008 (1) & & & & \\
\hline & reduced & $\mathrm{U}-\mathrm{Fe}_{1}$ & $6^{\mathrm{a}}$ & $3.14(2)$ & $0.012(2)$ & & & & \\
\hline & & $\mathrm{U}-\mathrm{Ca}_{1}$ & $2^{\mathrm{a}}$ & $3.43(2)$ & 0.005 (3) & & & & \\
\hline & & $\mathrm{U}-\mathrm{U}_{1}$ & $3^{a}$ & $3.90(2)$ & $0.006(2)^{\mathrm{b}}$ & & & & \\
\hline & & $\mathrm{U}-\mathrm{U}_{2}$ & $1^{\mathrm{a}}$ & $4.20(8)$ & $0.006(2)^{b}$ & & & & \\
\hline
\end{tabular}

$\mathrm{CN}$ denotes coordination number; $\mathrm{R}+\Delta \mathrm{R}$ denotes atomic distance; $\sigma^{2}$ denotes Debye-Waller factor; $\Delta E_{0}$ denotes the shift in energy from the calculated Fermi level; $\mathrm{S}^{2}$ denotes the amplitude factor; $\chi_{\mathrm{v}}^{2}$ denotes the reduced Chi square value; $R$ denotes the 'goodness of fit' factor. ${ }^{a}$ Parameter was fixed. ${ }^{b}$ Parameters were tied in a given fit. $\mathrm{S}^{2}$ was restrained to a value between $0.8-1.0$. Numbers in parentheses are one standard deviation on the last decimal place.

uranate in systems with and without mineral phases present (Bots et al., 2014; Smith et al., 2014). This suggests that during coprecipitation the U(VI) interaction with the crystallizing magnetite was via a nanoparticulate colloidal phase and not via ionic solution species, leading to the possibility of nanoparticulates adsorbed to the magnetite surface, and even potentially entrapped Ca-uranate inclusions within the iron oxide particles.

Incorporation of uranium into magnetite has previously been modelled using atomistic (Kerisit et al., 2011) and quantum-mechanical (ShullerNickles et al., 2014) approaches. The atomistic approach modelled the structure using incorporated $\mathrm{U}(\mathrm{IV}), \mathrm{U}(\mathrm{V})$ and $\mathrm{U}(\mathrm{VI})$ atoms in both octahedral and tetrahedral sites (Kerisit et al., 2011). In contrast, the quantum mechanical modelling used specific incorporation modes including: U(VI) incorporation into an octahedral site coupled with either octahedral or tetrahedral vacancies; and U(IV) incorporation into an octahedral site with either creation of an octahedral vacancy or $\mathrm{Fe}$ (III) reduction to $\mathrm{Fe}$ (II) to maintain charge balance (Shuller-Nickles et al., 2014). In the latter study, incorporation of U(VI) in an octahedral site in place of an $\mathrm{Fe}$ (III), with creation of an octahedral $\mathrm{Fe}$ (III) site vacancy was considered the most energetically favourable. Furthermore, they reported a U-Fe coordination of 4 rather than 6 for charge compensation purposes. With this arrangement, the $\mathrm{U}-\mathrm{Fe}_{1}$ atomic distances refined to $3.08 \AA$, whilst the equatorial $\mathrm{U}-\mathrm{O}_{2}$ distances were $2.13 \AA$. These are in close agreement with the refined interatomic distances and coordination numbers in the best fit model presented in Table 1 .

However, in the study of Shuller-Nickles et al. (2014) the axial U- $\mathrm{O}_{1}$ distance was $2.26 \AA$, longer than their equatorial $\mathrm{U}-\mathrm{O}_{2}$ distance, and significantly longer than the 1.8-1.9 $\AA$ observed here, and suggesting a component of adsorbed U(VI) in the current study. The equivalent model from atomistic simulations (Kerisit et al., 2011) does not distinguish between axial and equatorial $\mathrm{O}$, however, the $\mathrm{U}-\mathrm{O}$ distance reported $(2.13 \AA)$ corresponds well with the average distance reported here (2.11-2.22 $\AA$ ) and from quantum-mechanical modelling (2.17 $\AA$ ) (Shuller-Nickles et al., 2014). The Fe coordination observed here agrees well with quantummechanical modelling (Shuller-Nickles et al., 
2014), but was in excess of that observed experimentally elsewhere (Huber et al., 2012). However, in contrast to the study of Huber et al. (2012), here U was present during magnetite formation, indicating that $\mathrm{U}$ incorporation occurs mainly in the rapid crystallization phase, but continues during ageing.

\section{Conclusions}

Chemical dissolution data suggest that uranium is incorporated into magnetite in both cement leachates ( $\mathrm{pH}$ 10.5-13.1). Partial oxidation resulted in some release of $\mathrm{U}(\mathrm{VI})$ but a significant fraction of incorporated uranium was retained (Fig. 2). XANES data suggest that $\mathrm{U}$ was present as $\mathrm{U}(\mathrm{V})$, although contributions from both U(IV) and U(VI) could not be excluded. Fitting of the EXAFS data suggests that $\mathrm{U}$, possibly as $\mathrm{U}(\mathrm{V})$, is incorporated into an expanded octahedral site within the magnetite structure in place of Fe. In the YCL coprecipitation sample, in addition to U(IV), some of the $\mathrm{U}$ appears to be present as a U(VI)-Cauranate phase. This is due to the formation of U(VI) colloids in the YCL as opposed to U(VI) being present as an aqueous species as predicted by PHREEQC modelling (Bots et al., 2014). Despite the formation of $\mathrm{U}(\mathrm{VI})$ colloids at high $\mathrm{pH}$, magnetite appears to have the ability to reductively immobilize $\mathrm{U}(\mathrm{VI})$ from solution through incorporation.

Magnetite is a common corrosion product of steel (Musić et al., 1993; Dodge et al., 2002), and may therefore potentially provide a pathway for significant incorporation and immobilization of uranium derived from radioactive waste contained within a geological disposal facility.

\section{Acknowledgements}

This work has was funded through the UK Natural Environment Research Council (NERC) BIGRAD consortium (NE/H007768/1) and Diamond Light Source beamtime grants SP7367, SP7593 and SP8070. The authors thank Steve Parry and Richard Doull for assistance at Diamond, and Paul Lythgoe, Mike Ward and John Waters for assistance with ICPMS, TEM and XRD analyses, respectively.

\section{References}

Berner, U.R. (1992) Evolution of pore water chemistry during degradation of cement in a radioactive waste repository environment. Waste Management, 12, 201-219.

Boland, D.D., Collins, R.N., Payne, T.E. and Waite, T.D. (2011) Effect of amorphous Fe(III) oxide transformation on the $\mathrm{Fe}(\mathrm{II})$-mediated reduction of $\mathrm{U}(\mathrm{VI})$. Environmental Science \& Technology, 45, 1327-1333.

Boland, D., Collins, R.N., Glover, C., Payne, T. and Waite, T.D. (2014) Reduction of U(VI) by Fe(II) during the $\mathrm{Fe}(\mathrm{II})$-accelerated transformation of ferrihydrite. Environmental Science \& Technology, 48, 9086-9093.

Bots, P., Morris, K., Hibberd, R., Law, G.T.W., Mosselmans, J.F.W., Brown, A.P., Doutch, J., Smith, A.J. and Shaw, S. (2014) Formation of stable uranium(VI) colloidal nanoparticles in conditions relevant to radioactive waste disposal. Langmuir, 30, 14396-14405.

Burns, P.C., Ewing, R.C. and Hawthorne, F.C. (1997) The crystal chemistry of hexavalent uranium: polyhedron geometries, bond-valence parameters, and polymerization of polyhedra. The Canadian Mineralogist, 35, 1551-1570.

Campbell, K.M., Veeramani, H., Urich, K.-U., Blue, L.Y., Giammar, D.E., Bernier-Latmani, R., Stubbs, J.E., Suvorova, E., Yabusaki, S., Lezama-Pacheco, J.S., Mehta, A., Long, P.E. and Bargar, J.R. (2011) Oxidative dissolution of biogenic uraninite in groundwater at Old Rifle, CO. Environmental Science \& Technology, 45, 8748-8754.

Catalano, J.G., Heald, S.M., Zachara, J.M. and Brown, G. E. (2004) Spectroscopic and diffraction study of uranium speciation in contaminated vadose zone sediments from the Hanford site, Washington State. Environmental Science \& Technology, 38, 2822-2828.

Clark, D.L., Hobart, D.E. and Neu, M.P. (1995) Actinide carbonate complexes and their importance in actinide environmental chemistry. Chemical Reviews, 95, 25-48.

Cornell, R.M. and Schwertmann, U. (2003) The Iron Oxides: Structure, Properties, Reactions, Occurences and Uses, 2nd edition. Wiley-VCH: Weinham.

Dardenne, K., Schäfer, T., Lindqvist-Reis, P., Denecke, M. A., Plaschke, M., Rothe, J. and Kim, J.I. (2002) Low temperature XAFS investigation on the lutetium binding changes during the 2-line ferrihydrite alteration process. Environmental Science \& Technology, 36, 5092-5099.

Dent, A.J., Cibin, G., Ramos, S., Smith, A.D., Scott, S.M., Varandas, L., Pearson, M.R., Krumpa, N.A., Jones, C.P. and Robbins, P.E. (2009) B18: A core XAS spectroscopy beamline for diamond. Journal of Physics: Conference Series, 190, 012039. Iop Publishing Ltd, Bristol.

Docrat, T.I., Mosselmans, J.F.W., Charnock, J.M., Whiteley, M.W., Collison, D., Livens, F.R., Jones, C. and Edmiston, M.J. (1999) X-ray absorption spectroscopy of tricarbonatodioxouranate $(\mathrm{V}),\left[\mathrm{UO}_{2}\left(\mathrm{CO}_{3}\right)_{3}\right]^{5-}$, in aqueous solution. Inorganic Chemistry, 38, 1879-1882. 
Dodge, C.J., Francis, A.J., Gillow, J.B., Halada, G.P., Eng, C. and Clayton, C.R. (2002) Association of uranium with iron oxides typically formed on corroding steel surfaces. Environmental Science \& Technology, 36, 3504-3511.

Fleet, M.E. (1981) The structure of magnetite. Acta Crystallographica Section B-Structural Science, 2549, 917-920.

Gorski, C.A., Nurmi, J.T., Tratnyek, P.G., Hofstetter, T.B. and Scherer, M.M. (2010) Redox behavior of magnetite: implications for contaminant reduction. Environmental Science \& Technology, 44, 55-60.

Hansel, C.M., Benner, S.G., Neiss, J., Dohnalkova, A., Kukkadapu, R.K. and Fendorf, S. (2003) Secondary mineralization pathways induced by dissimilatory iron reduction of ferrihydrite under advective flow. Geochimica et Cosmochimica Acta, 67, 2977-2992.

Huber, F., Schild, D., Vitova, T., Rothe, J., Kirsch, R. and Schäfer, T. (2012) U(VI) Removal kinetics in presence of synthetic magnetite nanoparticles. Geochimica et Cosmochimica Acta, 96, 154-173.

Ilton, E.S., Boily, J.F., Buck, E.C., Skomurski, F.N., Rosso, K.M., Cahill, C.L., Bargar, J.R. and Felmy, A. R. (2010) Influence of dynamical conditions on the reduction of $\mathrm{U}(\mathrm{VI})$ at the magnetite-solution interface. Environmental Science \& Technology, 44, 170-176.

Ilton, E.S., Pacheco, J.S.L., Bargar, J.R., Shi, Z., Liu, J., Kovarik, L., Engelhard, M.H. and Felmy, A.R. (2012) Reduction of U(VI) incorporated in the structure of hematite. Environmental Science \& Technology, 46, 9428-9436.

Kahlweit, M. (1975) Ostwald ripening of precipitates. Advances in Colloid and Interface Science, 5, 1-35.

Kerisit, S., Felmy, A.R. and Ilton, E.S. (2011) Atomistic simulations of uranium incorporation into iron (hydr) oxides. Environmental Science \& Technology, 45, 2770-2776.

Latta, D.E., Mishra, B., Cook, R.E., Kemner, K.M. and Boyanov, M.I. (2014) Stable U(IV) complexes form at high-affinity mineral surface sites. Environmental Science \& Technology, 48, 1683-1691.

Lloyd, J.R. and Renshaw, J.C. (2005) Bioremediation of radioactive waste: radionuclide-microbe interactions in laboratory and field-scale studies. Current Opinion in Biotechnology, 16, 254-260.

Marshall, T.A., Morris, K.M., Law, G.T.W., Mosselmans, J.F.W., Bots, P., Parry, S.A. and Shaw, S. (2014a) Incorporation and retention of 99-Tc(IV) in magnetite under high $\mathrm{pH}$ conditions. Environmental Science \& Technology, 48, 11853-11862.

Marshall, T.A., Morris, K., Law, G.T.W., Livens, F.R., Mosselmans, J.F.W., Bots, P. and Shaw, S. (2014b) Incorporation of uranium into hematite during crystallization from ferrihydrite. Environmental Science \& Technology, 48, 3724-3731.
Missana, T., Maffiotte, U. and García-Gutiérrez, M. (2003) Surface reactions kinetics between nanocrystalline magnetite and uranyl. Journal of Colloid and Interface Science, 261, 154-160.

Moyce, E.B.A., Rochelle, C., Morris, K., Milodowski, A. E., Chen, X., Thornton, S., Small, J.S. and Shaw, S. (2014) Rock alteration in alkaline cement waters over 15 years and its relevance to the geological disposal of nuclear waste. Applied Geochemistry, 50, 91-105.

Murphy, W.M. and Shock, E.L. (1999) Environmental aqueous geochemistry of actinides. Pp. 221-253. in: Uranium: Mineralogy, Geochemistry, and the Environment (P.C. Burns and R. Finch, editors). Reviews in Mineralogy, 38. Mineralogical Society of America, Washington DC.

Musić, S., Gotić, M. and Popović, S. (1993) X-ray diffraction and Fourier-transform infrared-analysis of the rust formed by corrosion of steel in aqueous-solutions. Journal of Materials Science, 28, 5744-5752.

Nico, P.S., Stewart, B.D. and Fendorf, S. (2009) Incorporation of oxidized uranium into Fe (hydr) oxides during $\mathrm{Fe}(\mathrm{II})$ catalyzed remineralization. Environmental Science \& Technology, 43, 7391-7396.

Payne, T.E., Davis, J.A. and Waite, T.D. (1994) Uranium retention by weathered schists - the role of iron minerals. Radiochimica Acta, 66/67, 297-303.

Ravel, B. and Newville, M. (2005) Athena, Artemis, Hephaestus: data analysis for X-ray absorption spectroscopy using IFEFFIT. Journal of Synchrotron Radiation, 12, 537-541.

Scott, T.., Allen, G.C., Heard, P.J. and Randell, M.G. (2005) Reduction of U(VI) to U(IV) on the surface of magnetite. Geochimica et Cosmochimica Acta, 69, 5639-5646.

Senko, J.M., Istok, J.D., Suflita, J.M. and Krumholz, L.R. (2002) In situ evidence for uranium immobilization and remobilization. Environmental Science \& Technology, 36, 1491-1496.

Senko, J.M., Kelly, S.D., Dohnalkova, A.C., McDonough, J.T., Kemner, K.M. and Burgos, W.D. (2007) The effect of U(VI) bioreduction kinetics on subsequent reoxidation of biogenic U(IV). Geochimica et Cosmochimica Acta, 71, $4644-4654$.

Shannon, R.D. (1976) Revised effective ionic-radii and systematic studies of interatomic distances in halides and chalcogenides. Acta Crystallographica Section A, 32, 751-767.

Shuibo, X., Chun, Z., Xinghuo, Z., Jing, Y., Xiaojian, Z. and Jingsong, W. (2009) Removal of uranium(VI) from aqueous solution by adsorption of hematite. Journal of Environmental Radioactivity, 100, 162-166.

Shuller-Nickles, L., Bender, W., Walker, S. and Becker, U. (2014) Quantum-mechanical methods for quantifying incorporation of contaminants in proximal minerals. Minerals, 4, 690-715. 
Sidhu, P.S., Gilkes, R.J. and Posner, A.M. (1977) Mechanism of the low temperature oxidation of synthetic magnetites. Journal of Inorganic and Nuclear Chemistry, 39, 1953-1958.

Sidhu, P.S., Gilkes, R.J. and Posner, A.M. (1978) The synthesis and some properties of $\mathrm{Co}, \mathrm{Ni}, \mathrm{Zn}, \mathrm{Cu}, \mathrm{Mn}$ and $\mathrm{Cd}$ substituted magnetites. Journal of Inorganic and Nuclear Chemistry, 40, 429-435.

Singer, D.M., Chatman, S.M., Ilton, E.S., Rosso, K.M., Banfield, J.F. and Waychunas, G.A. (2012a) Identification of simultaneous U(VI) sorption complexes and U(IV) nanoprecipitates on the magnetite (111) surface. Environmental Science \& Technology, 46, 3811-3820.

Singer, D.M., Chatman, S.M., Ilton, E.S., Rosso, K.M., Banfield, J.F. and Waychunas, G.A. (2012b) U(VI) sorption and reduction kinetics on the magnetite (111) surface. Environmental Science \& Technology, 46, 3821-3830.

Skomurski, F.N., Ilton, E.S., Engelhard, M.H., Arey, B.W. and Rosso, K.M. (2011) Heterogeneous reduction of $\mathrm{U}^{6+}$ by structural $\mathrm{Fe}^{2+}$ from theory and experiment. Geochimica et Cosmochimica Acta, 75, 7277-7290.

Smith, K.F., Bryan, N.D., Swinburne, A.N., Bots, P., Shaw, S., Natrajan, L.S., Mosselmans, J.F.W., Livens, F.R. and Morris, K. (2014) U(VI) behaviour in hyperalkaline calcite systems. Geochimica et Cosmochimica Acta, 148, 343-359.

Soldatov, A.V., Lamoen, D., Konstantinović, M.J., Van den Berghe, S., Scheinost, A.C. and Verwerft, M. (2007) Local structure and oxidation state of uranium in some ternary oxides: X-ray absorption analysis. Journal of Solid State Chemistry, 180, 54-61.

Stewart, B.D., Nico, P.S. and Fendorf, S. (2009) Stability of uranium incorporated into $\mathrm{Fe}$ (hydr)oxides under fluctuating redox conditions. Environmental Science \& Technology, 43, 4922-4927.

Tang, J., Myers, M., Bosnick, K.A. and Brus, L.E. (2003) Magnetite $\mathrm{Fe}_{3} \mathrm{O}_{4}$ nanocrystals: spectroscopic observation of aqueous oxidation kinetics. Journal of Physical Chemistry B, 107, 7501-7506.
Van den Berghe, S., Verwerft, M., Laval, J.-P., Gaudreau, B., Allen, P.G. and Van Wyngarden, A. (2002) The local uranium environment in cesium uranates: a combined XPS, XAS, XRD, and neutron diffraction analysis. Journal of Solid State Chemistry, 166, 320-329.

Viollier, E., Inglett, P.W., Hunter, K., Roychoudhury, A.N . and Van Cappellen, P. (2000) The ferrozine method revisited: $\mathrm{Fe}(\mathrm{II}) / \mathrm{Fe}(\mathrm{III})$ determination in natural waters. Applied Geochemistry, 15, 785-790.

Waite, T.D., Davis, J.A., Payne, T.E., Waychunas, G.A. and $\mathrm{Xu}, \mathrm{N}$. (1994) Uranium(VI) adsorption to ferrihydrite-application of a surface complexation model. Geochimica et Cosmochimica Acta, 58, 5465-5478.

Wallace, S.H., Shaw, S., Morris, K., Small, J.S., Fuller, A.J. and Burke, I.T. (2012) Effect of groundwater $\mathrm{pH}$ and ionic strength on strontium sorption in aquifer sediments: implications for $90 \mathrm{Sr}$ mobility at contaminated nuclear sites. Applied Geochemistry, 27, 1482-1491.

Wallace, S.H., Shaw, S., Morris, K., Small, J.S. and Burke, I.T. (2013) Alteration of sediments by hyperalkaline K-rich cement leachate: implications for strontium adsorption and incorporation. Environmental Science \& Technology, 47, 3694-3700.

Walter, M., Somers, J., Bouëxière, D., Gaczyński, P. and Brendebach, B. (2009) Oxidation behaviour of uranium and neptunium in stabilised zirconia. Journal of Solid State Chemistry, 182, 3305-3311.

Wellman, D.M., Mattigod, S.V., Arey, B.W., Wood, M.I. and Forrester, S.W. (2007) Experimental limitations regarding the formation and characterization of uranium-mineral phases in concrete waste forms. Cement and Concrete Research, 37, 151-160.

Yanina, S.V. and Rosso, K.M. (2008) Linked reactivity at mineral-water interfaces through bulk crystal conduction. Science (New York), 320, 218-222. 